\title{
Reducing Diabetic Blindness in Far-Flung Sub-Saharan Rural Communities: Odot, Nsit-Atai as a Case Study
}

\author{
Emmanuel Olu Megbelayin', Margaret Mboho² \\ ${ }^{1}$ Department of Ophthalmology, University of Uyo, Uyo, Nigeria \\ ${ }^{2}$ Department of Physical and Health Education, University of Uyo, Uyo, Nigeria \\ Email: favouredolu@yahoo.com
}

Received 18 October 2014; revised 22 November 2014; accepted 7 December 2014

Copyright (C) 2014 by authors and OALib.

This work is licensed under the Creative Commons Attribution International License (CC BY). http://creativecommons.org/licenses/by/4.0/

(c) (i) Open Access

\begin{abstract}
Background: Odot is the head-quarter of Nsit-Atai local government, 70 kilometers from Uyo, the Akwa-Ibom state capital. About 5000 population has a Comprehensive Health Center, a Primary Health Centre and 2 Health Posts to meet its enormous health needs. Additionally, the workers in these health facilities are neither trained nor equipped to render eye care services. Patients with systemic diseases with potentially debilitating effects on vision come to the urban tertiary referral health center at terminal blinding stages. This trend requires an urgent attention to curb diabetic blindness among often vibrant working population. Objective: To explore how scheduled vision screening exercises can help reduce blindness from diabetic mellitus in this rural community. Methodology: Major databases including National library of Medicine PubMed were searched for relevant data. Additional information was obtained by on-sight assessment of the index community. Conclusion: From community health standpoint, vision screening remains a cheap avenue to arrest diabetic blindness in Nsit-Atai and similar set-ups around the world.
\end{abstract}

\section{Keywords}

Diabetes Mellitus, Blindness, Health Planning, Eye Screening, Medical Economics

Subject Areas: Ophthalmology, Public Health

\section{Introduction}

Diabetic mellitus (DM) is a metabolic disease that remains a major cause of blindness globally. DM has been a source of concern to the developed world having been linked with debilitation and mortality. With the change in lifestyle which has not spared rural communities in developing world, diseases that are known to be uncommon 
in this environment have continued to be sources of economic drain to an already impoverished population [1]. The incidence and prevalence of blindness is much lower in populations where screening for diabetic eye disease has been established compared to diabetic populations without screening [2]-[5]. Screening programs are economically viable as the costs of treating diabetes constitute a huge economic burden. Furthermore, treatment of late disease is fraught with failures, loss of man-hour and issues that border on compliance to regimented treatment schedules. This paper explores a broad-based community approach to vision screening in a typical Nigerian rural settlement. It is expected that the information derived from the article will be applicable to similar populations around the world towards eye health promotion and curbing avoidable blindness.

\section{Magnitude of the Problem}

DM is a well-known major public health problem world-wide [6]. Due to a lack of proper awareness and health education, diabetes sufferers are particularly prone to complications of which ocular complications are most distressing [7]. International Diabetes Federation reported that cases of DM in Africa have nearly doubled to more than 7 million within the past 15 years [8]. Nwafor et al. [9] have established that Nigerians have the propensity to have DM. The growing adoption of Western lifestyle is a plausible contribution. According to Adefemi [10], it has been estimated that the number of people with diabetes in Nigeria is presently over 1.5 million. This is an indication that the disease is spreading widely and silently in the country.

The percentage of undiagnosed cases of DM was $18.9 \%$ in a Port-Harcourt study [9]. This is expected to be much higher in a rural community like Nsit-Atai, with dearth of health facilities. Duration of DM is the single most important risk factor to developing diabetic retinopathy (DR), a visually devastating ocular complication of diabetes. Forster reported that DR contributed 5\% to global blindness [11]. This trend was reported in Nigeria with DR constituting a major cause of blindness in an Onitsha hospital-based study [12].

\section{Community-Based Vision Screening among Rural Diabetics}

\subsection{Sources of Program Financing}

Many avenues abound to raise funds for vision screening programs. Broadly speaking, governmental and nongovernment organizations are available sources in resource-limited economies of developing world. The impacts of international agencies like Sight-Savers International, Helen Keller Foundation among others have continued to be felt in sub-Saharan Africa and beyond. Politicians at the local government level, community representatives in state and federal legislative houses are yet untapped areas. Indeed, a compromise that allows screening programs to be tagged with the slogan or with the name of a popular politician to solicit for sponsorship can easily be reached.

\subsection{Community Entry and Advocacy}

In sponsored program, the sponsors can ease access to the community especially if they come from that community. Key to acceptance of community-based health interventions is the approach such interventions are presented to the target population. Opinion leaders, traditional rulers, political leaders, religious leaders, age groups, representative of market women among others are members of the community that can be approached to enhance community participation. Advocacy visits to influential persons and groups will also help dispel fears and anxiety of a program by non-members of the community.

\subsection{Training of Team Members}

Team member will include staff of the community health facility and eye care workers from outside the community. These eye care workers will include ophthalmologists, optometrists, ophthalmic nurses and support staff. Primary eye care worker can be integrated into the existing health facility. Community volunteers can be trained to alert on sinister ocular signs and symptoms. By engaging members of the community, there is community participation and ownership.

\subsection{Execution of Program}

The duration of actual screening exercise will depend on the target population. A few days are often sufficient 
based on the resources available. It is not feasible to conduct vision screening on all participants. Therefore, those with history of DM or abnormal sugar level confirmed with glucose strip test should have vision screening.

Program should be executed when the community members will be most available. It should not be during traditional festivals, market days or days when community members will have statutory engagements. Documentation is key to enable program evaluation. Participants' data should include: demographic profile, Body Mass Index (BMI), duration of DM, metabolic regulation (glycosylated haemoglobin), presenting systemic complications traceable to DM (e.g. amputation), and associated systemic hypertension, information of diabetic treatment including compliance.

Record of previous eye disease or treatment (cataract, glaucoma, glasses, and trauma) is also vital. Screening should include visual acuity determination with Snellen's chart (both literate and illiterate charts), pen light examination of the anterior segment of the eye and dilated fundoscopy. Glasses, antibiotics and anti-allergic drugs can be dispensed free to those in need. This will encourage more people to participate. Identified cases of diabetic eye disease or those with long duration of DM, 10 years and above are referred to the urban tertiary center for follow-up and treatment under a sponsored or subsidized scheme.

\subsection{Barriers to Early Hospital Presentation among Diabetics in Rural Communities}

Economic wherewithal has been the bane of seeking early medical attention in impoverished nations of Africa and Asia [13] [14]. Lopsided distribution of healthcare services whereby eye care providers tend to be found in the cities, dissuading peer group, ignorance about availability of treatment for a compromised vision play additional key roles. Socio-cultural beliefs that attach supernatural forces to medical conditions have continued to thwart concerted efforts to prevent avoidable disability and mortality in our African settings.

\subsection{Accessing Hard to Reach Members of the Community}

Some members of the society could be difficult to access. This could be due to previous unpleasant experience with similar programs, ignorance, and skepticism about a program organized by unknown people. A town crier is a designated member of the community that goes round in early morning hours to inform them of a new development using a megaphone. Services of a town crier, regional radio and television programs and posters can be useful.

\subsection{Monitoring}

There should be clear indicators for monitoring and program improvement, and to measure success and challenges. It should also make provision for independent evaluation by governmental agencies and program sponsors.

\subsection{Program Evaluation}

This involves collecting relevant data from patients with DM or family members, available health records, and program participants. Observation, opinionnaires, questionnaires are additional tools for data gathering. The data should be analyzed using simple statistics that can easy be understood. The outcome of evaluation could be presented to agencies for sponsorship of future programs or ploughed back into future programs. Importantly, trust is established between program sponsors and executors when evaluation shows accountability.

\section{Conclusion}

The current gap between eye care providers and the many cases of diabetic blindness is unacceptable, and could be best bridged through community-based vision screening. Given the dysfunctional nature of eye care systems in many impoverished parts of the world, it could be best bridged through the establishment of permanent eye care structures and services that feed well-equipped facilities in urban centers at no cost or affordable cost. Furthermore, these facilities should be acceptable socio-culturally to the target community to enable unfettered patronage. 


\section{References}

[1] Adeleye, J.O., Agada, N.O., Balogun, W.O., Adetunji, O.R. and Onyegbutulem, H.O. (2006) Diabetes Care in Nigeria: Time for a Paradigm Shift. Africa Journal of Medicine and Medical Sciences, 35, 155-159.

[2] Einar, S., Toke, B., Porta, M., Larsen, N., Johannes, K. and Agardh, E. (2000) Screening and Prevention of Diabetic. Acta Ophthalmologica Scandinavica, 78, 374-385. http://dx.doi.org/10.1034/j.1600-0420.2000.078004374.x

[3] Agardh, E., Agardh, C.-D., Hansson-Lundblad, C. and Cavallin, S.U. (1996) The Importance of Early Diagnosis of Treatable Diabetic Retinopathy for the Four-Year Visual Outcome in Type 2 Diabetes Mellitus. Acta Ophthalmologica Scandinavica, 74, 166-170. http://dx.doi.org/10.1111/j.1600-0420.1996.tb00064.x

[4] Henricsson, M., Tyrberg, M., Hejl, A. and Janzon, L. (1996) Incidence of Blindness and Visual Impairment in Diabetic Patients Participating in an Ophthalmological Control and Screening Programme. Acta Ophthalmologica Scandinavica, 74, 533-538. http://dx.doi.org/10.1111/j.1600-0420.1996.tb00729.x

[5] Kristinsson, J.K., Hauksdottir, H., Stefansson, E., Jonasson, F. and Gislason, I. (1997) Active Prevention in Diabetic Eye Disease. Acta Ophthalmologica Scandinavica, 75, 249-254. http://dx.doi.org/10.1111/j.1600-0420.1997.tb00766.x

[6] WHO (2004) The Global Burden of Disease: 2004 Update. World Health Organization, Geneva.

[7] Harande, Y.I. (2011) Exploring the Literature of Diabetes in Nigeria: A Bibliometrics Study. African Journal of Diabetes Medicine, 2, 1-4.

[8] (2009) Diabetes-Deadly, Un-Funded and Unidentified. International Diabetes Federation, Africa. http://www.irinnews.org/report.aspx?ReportId=83280

[9] Nwafor, A. and Owhoji, A. (2001) Prevalence of Diabetes Mellitus among Nigerians in Port Harcourt Correlates with Socio-Economic Status. Journal of Applied Science and Environment Management, 5, 75-77.

[10] Adefemi, K. (2009) What You Need to Know about Diabetes. http://ezine articles.com/?What-You-Need-To-Know-About-Diabetes\&id=22656

[11] Foster, A. and Resnikoff, S. (2005) The Impact of Vision 2020 on Global Blindness. Eye, 19, 1133-1135. http://dx.doi.org/10.1038/sj.eye.6701973

[12] Nwosu, S.N.N. (2000) Prevalence and Pattern of Retinal Diseases at the Guinness Eye Hospital, Onitsha, Nigeria. Ophthalmic Epidemiology, 1, 41-48. http://dx.doi.org/10.1076/0928-6586(200003)711-2FT041

[13] Pepper, D.J., Levitt, N.S., Cleary, S. and Burch, V.C. (2007) Hyperglycaemic Emergency Admissions to a SecondaryLevel Hospital-An Unnecessary Financial Burden. South Africa Medical Journal, 97, 963-967.

[14] World Health Organization (2008) 2008-2013 Action Plan for the Global Strategy for the Prevention and Control of Non-Communicable Diseases. WHO, Geneva. 